\title{
Governação pública em rede \\ Contributos para sua compreensão e análise (em Portugal e no Brasil) ${ }^{1}$
}

\author{
Luis F. Mota* \\ https://orcid.org/0000-0003-0618-8553 \\ Bernadete Bittencourt* \\ https://orcid.org/0000-0002-1620-314X
}

\section{Introdução}

O crescente recurso a formas de governação pública em rede, através da participação de um maior número e diversidade de atores nos processos de formulação e implementação de políticas públicas, poderá ser considerado uma das principais mudanças ocorridas no âmbito da governação pública de diversos países ocidentais no decurso das últimas décadas, sobretudo desde a década de 90 do século xx (ver, inter alia, Sørensen e Torfing (2007), Mandell (2014), Klijn e Koppenjan (2016)). De acordo com alguns autores, esse fenômeno decorre de fatores como a crescente especialização e a decorrente fragmentação das entidades públicas, a complexificação dos contextos de atuação dos Estados e dos problemas societais, bem como o aumento de atitudes críticas face às autoridades políticas tradicionais ou do surgimento de novos movimentos cívicos participativos (Kooiman, 1993; Rhodes, 1997; Kickert et al., 1997).

* Universidade de Aveiro, Aveiro, Portugal.

1. Este artigo foi desenvolvido no âmbito do projeto "Decide: Governação Territorial Descentralizada: coordenação, capacidade e responsabilização em arranjos de governação local em contextos regionais complexos" (Poci-01-0145-Feder-032502), financiado pelo Programa Operacional Competitividade e Internacionalização (Feder) e pela Fundação para a Ciência e a Tecnologia, e no âmbito da bolsa de pós-doutoramento do primeiro autor (SFRH/BPD/115117/2016), financiada pela Fundação para a Ciência e a Tecnologia. Os autores agradecem às doutoras Maria E. Cardim e Sara Moreno Pires, revisores anônimos e equipe de editores pelos comentários a versões preliminares deste artigo. 
O cenário acima descrito tem determinado o advento de um amplo conjunto de formas de governação pública interativa, que, segundo Mandell (2014), poderão ser incluídas sob o termo agregador de "arranjos baseados na governação em rede" (network-governance-based arrangements). São exemplos dessas formas de governação as redes de governação, propriamente ditas, as parcerias público-privadas, ou ainda iniciativas comunitárias, contratos, joint-ventures, alianças estratégicas, entre outras, cuja natureza interativa dá corpo ao designado "modo de governação em rede” (Sullivan e Skelcher, 2002; Sørensen e Torfing, 2007).

Considerando a enorme importância da governação em rede nas realidades políticas de diversos países, esta vem a ser alvo de um crescente, embora ainda reduzido, interesse acadêmico e político (Sørensen e Torfing, 2007; Klijn e Koppenjan, 2016). Apesar de a realidade portuguesa e a brasileira não serem exceção a essa tendência de reforma de governação, o interesse pelo fenômeno é ainda escasso entre os acadêmicos e políticos de ambos os países (Mota et al., 2016; Mota et al., 2014; Gomes e Secchi, 2015). A pouca atenção a esse fenômeno torna-se, contudo, particularmente problemática quando o recurso a esse modo de governação é frequente, ainda que nem sempre bem-sucedido, ao mesmo tempo que a falta de uma cultura de parceria e negociação entre atores nos mais diversos níveis é apontada como um claro problema para as políticas públicas em ambos os países (Mota et al., 2014; Gomes e Secchi, 2015).

Este artigo pretende, assim, apresentar um ensaio sobre o fenômeno da governação pública em rede: atribuindo-se especial enfoque às redes de governação, propriamente ditas, e às parcerias ${ }^{2}$ enquanto formas de governação, será elaborada uma reflexão sobre os fatores críticos subjacentes a práticas de governação pública em rede em Portugal e no Brasil. Esta revisão da literatura irá cobrir temáticas diversas, tais como a identificação das principais características distintivas da governação em rede face a outros modos de governação, as diferentes tipologias de redes e os benefícios e desafios que lhes estão inerentes (seção II), as principais abordagens teóricas e metodológicas do seu estudo (seção III), ou os fatores críticos para o sucesso das redes (seção IV). O artigo termina com uma reflexão sobre a aplicação desta literatura aos casos português e brasileiro (seção v) e algumas notas finais (seção VI).

2. Para efeitos de simplificação, redes de governação e parcerias serão entendidas neste artigo como formas de governação relativamente semelhantes, na medida em que, apesar de terem algumas diferenças entre si, apresentam diversas semelhanças enunciadas por vários autores (ver, inter alia, Torfing et al., 2012; Sullivan e Skelcher, 2002). 
II. Redes e parcerias de governação pública: características, tipologias, benefícios e desafios

Como aludido na seção introdutória, o aumento do recurso a formas de governação mais interativas resulta da consciência sobre a interdependência entre atores societais e políticos, advinda da crescente complexidade dos problemas e da fragmentação funcional e especialização entre diferentes atores (Torfing $e t$ al., 2012). A adequação das redes (e das parcerias) a esse contexto decorre do fato de serem formas de governação com uma "1. articulação relativamente estável e horizontal de atores interdependentes, embora operacionalmente autónomos; 2. que interagem através de negociações; 3 . a qual tem lugar num quadro regulativo, normativo, cognitivo e imaginário; 4. que é autorregulado dentro dos limites definidos por agências externas; 5. e que contribui para a prossecução de fins públicos" (Sørensen e Torfing, 2007, p. 9).

A governação em rede, que assumiu maior destaque no âmbito da designada Nova Governação Pública, apresenta, assim, diferenças face a outros modos de governação como a hierarquia ou os mercados, que vinham dominando a governação pública até então (Osborne, 2010). Como é possível observar na figura 1, as redes distinguem-se dos demais modos de governação pelo fato de, entre outras coisas, os atores terem relações de interdependência entre eles devido à complementaridade de forças, a gestão de relações ter como base os princípios de reciprocidade e de negociação, e pelo fato de as suas finalidades serem a obtenção de benefícios mútuos.

FIGURA 1

Comparação entre modos de governação: hierarquia, mercado e redes

\begin{tabular}{l|l|l|l}
\hline Modo De Governação & \multicolumn{1}{|c|}{ Hierarquia } & \multicolumn{1}{|c}{ Mercado } & \multicolumn{1}{c}{ Redes } \\
\hline Tipo DE RELAÇÕES & Hierárquicas & Autônomas & Interdependentes \\
\hline BASE RELACIONAL & Comando e controlo & Trocas e competição & Cooperação \\
\hline BASE NORMATIVA & Rotinas e supervisão & Normas contratuais e preços & Cuidados reputacionais e negociação \\
\hline CoNTROLO E AVALIAÇão & $\begin{array}{l}\text { Normas e padrões, } \\
\text { rotinas e supervisão } \\
\text { (gestão via inputs) }\end{array}$ & $\begin{array}{l}\text { Padrões de desempenho e } \\
\text { cumprimento de contratos } \\
\text { (gestão via outputs) }\end{array}$ & $\begin{array}{l}\text { Ativação e gestão de parcerias } \\
\text { e prossecução de objetivos comuns } \\
\text { (gestão via outcomes) }\end{array}$ \\
\hline
\end{tabular}

Fonte: Produção própria, com base em Bouckaert et al. (2010), Osborne (2010) e Klijn e Koppenjan (2016).

Outro aspecto que importa salientar em relação às redes e parcerias é que se constituem como formas de governação que podem assumir enorme diversidade de 
formatos e desempenhar um amplo e diversificado conjunto de funções ao longo de todo o processo de políticas públicas (Torfing, 2012; Sullivan e Skelcher, 2002).

Quanto aos formatos, Torfing (2012) refere, por exemplo, que as redes e parcerias podem ser iniciadas por diferentes atores - nomeadamente, autoridades públicas de topo (top-down) ou funcionários e/ou organizações implementadoras a operar no terreno ou movimentos de cidadãos (bottom-up) -, podem ter maior ou menor proximidade entre parceiros, e ter uma duração curta ou permanente.

Já ao nível das operações que executam, têm sido diversos os autores que se dedicam a estudar as diferentes tipologias de funções das redes. Entre diversas tipologias, poder-se-ão destacar as propostas de Agranoff (2003), que distingue redes de informação, de desenvolvimento, de outreach e de ação, e as de Keast, Brown e Mandell (2007), que distinguem três tipos de redes: as redes de cooperação, as de coordenação e as de colaboração - veja-se figura 2. Da análise de ambas as tipologias, é possível verificar-se que os diferentes tipos de redes propostos comportam distintos níveis de ambição e compromisso, tal como é possível observar na Figura 2.

FIGURA 2

Comparação entre tipologias de redes por nivel de ambição e compromisso

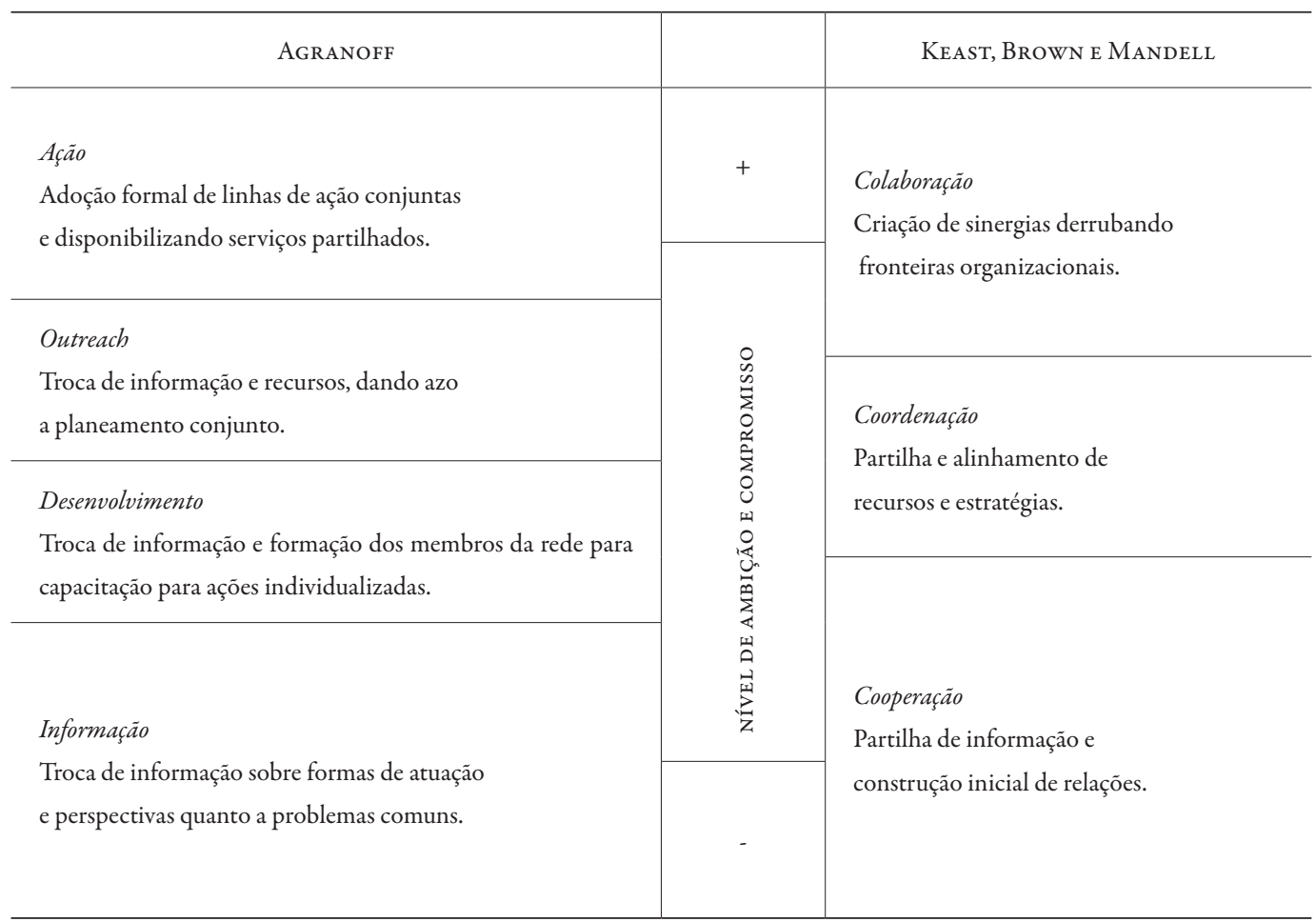

Fonte: Produção própria, com base em Agranoff (2003) e Keast et al. (2007). 
Diante da enorme multiplicidade de funçôes que poderão desempenhar, não será de estranhar que o apelo ao recurso a redes e parcerias no âmbito da governação pública esteja associado a um amplo conjunto de possíveis benefícios. McQuaid (2010) enuncia, a esse propósito, um conjunto diversificado de potenciais benefícios das parcerias, nomeadamente: (a) promoção de decisões reforçadas por um alto nível de legitimidade e validade; (b) possibilidade de desenvolvimento de soluções mais flexíveis e rápidas, por serem menos politizadas; (c) promoção da inovação; (d) fomento da partilha de recursos físicos e de conhecimento, promovendo a criação de sinergias; (e) desenvolvimento de coerência nos serviços; e (f) melhoria da eficiência e da accountability.

Não obstante esse amplo conjunto de vantagens, o recurso a formas de governação interativa não pode ser considerado como uma panaceia, na medida em que tem também diversas desvantagens e limitações. Peters (2010) refere, a esse propósito, que os problemas mais frequentes relacionados com o recurso a redes na fase de tomada de decisão podem ser agrupados nos seguintes quatro tipos: no nível da decisão, decisões de qualidade mais reduzida, dada a potencial tendência para a negociação entre parceiros se realizar pelo "mínimo denominador comum"; no nível da participação, a atuação em rede pode ter a tendência a tornar-se elitista e circunscrita a um conjunto restrito de grupos de interesse, ao invés de ser inclusiva; no nível da coordenação, dificuldade de coordenar a atuação de diferentes organizações, dada a excessiva fragmentação e especialização das mesmas; e, no nível da accountability, diminuição da capacidade de controlo das ações dos diversos atores intervenientes, por parte do poder político e dos cidadãos.

Para além dessas questóes acima referidas, as redes de governação podem ainda ter problemas associados com a morosidade dos processos de decisão e os respetivos custos, com o conflito entre atores no respeitante à natureza dos problemas e das intervenções, com as diferenças organizacionais em termos de práticas e filosofias de ação, com a definição pouco clara de papéis e responsabilidades, ou ainda com a falta de preparação e empoderamento de alguns atores-chave (por exemplo, grupos de cidadãos) (McQuaid, 2010).

Face à constatação de tais problemas, os estudos sobre redes de governação vêm a afastar-se da mera análise das características distintivas das redes (primeira geração de estudos) e a focar-se mais na identificação de fatores críticos de sucesso e no reconhecimento das diferentes tipologias das redes, dando lugar a uma multiplicidade de abordagens teóricas e metodológicas (segunda geração de estudos) (Sørensen e Torfing, 2007). Na sequência, abordar-se-ão os pontos principais da diversidade de abordagens teóricas e metodológicas no estudo das redes de governação. 


\section{A diversidade de abordagens teóricas e metodológicas no estudo das redes de governação pública}

A análise científica da governação pública em rede ganhou mais destaque a partir da década de 90 do século xx devido a contributos de estudos seminais como os de Mandell (1990), Kooiman (1993), Rhodes (1997), ou Kickert et al. (1997), entre outros. Muito embora tenha sido nessa década que o tema das redes recebeu maior atenção, Klijn e Koppenjan (2016) frisam que as raízes do estudo da governação em rede remontam às décadas de 60 e 70 do século $\mathrm{xx}$, quando o tema das relações interorganizacionais começou a ganhar alguma relevância no âmbito da teoria organizacional, da ciência política e da ciência das políticas públicas. A esse propósito, esses autores (Klijn e Koppenjan, 2016) referem haver diferenças assinaláveis entre a influência dessas três disciplinas, a ponto de terem dado origem às três seguintes tradições de investigação, as quais diferem quanto ao foco e à raiz disciplinar, entre outros aspectos:

- Tradição das redes de (formulação de) políticas públicas (policy networks), cuja raiz disciplinar é a Ciência Política, que tem por enfoque as relações de poder e os níveis de abertura dos processos de tomada de decisão, sendo G. Jordan, Rob Rhodes, ou Frank Baumgartner e Bryan Jones alguns dos seus principais autores.

- Tradição da governação colaborativa e em rede (collaborative and network governance), que tem na Administração Pública e no Planeamento Colaborativo as principais raízes disciplinares, que se foca nos processos de deliberação sobre problemas societais e na gestão de relações horizontais entre atores formais e informais, e que tem como principais autores Myrna Mandell, Walter Kickert, Erik-Hans Klijn e Joop Koppenjan, Robert Agranoff e Michael McGuire, bem como Eva Sørensen e Jacob Torfing.

- Tradição das redes de provisão de serviços (service delivery and implementation networks), cuja raiz disciplinaréa teoria (inter)organizacional, que se foca nas temáticas da eficácia das políticas e da provisão e da coordenação interorganizacional e cujos principais autores de referência são Brinton Milward, Keith Provan e Patrick Kenis.

Apesar de a análise do fenômeno da governação interativa possuir, assim, raízes mais remotas, o interesse acrescido desde o final do século $\mathrm{xx}$ trouxe algumas novidades, nomeadamente o fato de esse modo de governação ter começado a ser visto como potencialmente eficaz e legítimo no âmbito da definição e implementação de intervenções direcionadas a problemas societais (Sørensen e Torfing 2007). Como referem Torfing et al. (2012), a abordagem da Governação Interativa (mais recente) difere da teoria pluralista (mais antiga), na medida em que esta última encara os atores 
não governamentais como grupos de pressão que competem entre si na tentativa de influenciar o processo de políticas públicas, ao passo que a primeira enfatiza a interação negociada entre diversos atores através da partilha de conhecimento, recursos e ideias.

A propósito da diversidade de abordagens na análise de redes, importa, por fim, destacar a existência de uma enorme diversidade de abordagens teóricas. Adotando uma perspectiva neoinstitucionalista, Sørensen e Torfing (2007; Torfing, 2012) identificam quatro abordagens teóricas, nomeadamente:

- Teoria da Interdependência, que, fortemente ancorada no institucionalismo histórico, define as redes de governação como uma mediação de interesses entre atores interdependentes, embora conflitantes, entendendo a formação de redes como maneira de os atores envolvidos encontrarem soluções conjuntas para problemas comuns e para contornar a fragmentação institucional; as redes se mantêm coesas pela interdependência mútua e pelo desenvolvimento de normas e percepções comuns.

- Teoria da Governabilidade, que, fortemente influenciada pelo institucionalismo de escolha racional, define as redes como formas de coordenação horizontal entre atores que interagem entre si, observando as redes como estruturas de "jogos" que promovem a negociação entre atores, que se mantêm coesas pela noção antecipada de ganhos e de partilha de recursos.

- Teoria de Integração Normativa, que, fortemente influenciada pelo institucionalismo sociológico, interpreta as redes como espaços de interação que congregam atores relevantes (stakeholders) num determinado domínio, sendo formadas por processos bottom-up que, se avaliados positivamente, dão origem a situações de isomorfismo, mantendo-se coesas através da emergência de regras e valores comuns.

- Teoria da Governamentalidade, que, fortemente influenciada pelo institucionalismo discursivo, define as redes como formas desenvolvidas pelo Estado com o objetivo de mobilizar e enquadrar ações livres de atores, considerando que as redes são desenhadas e enquadradas por narrativas que tentam mobilizar esses atores para exercerem poder.

Muito embora a diversidade de abordagens acima referida seja um claro sinal de que o fenômeno das redes ocupa um espaço central na ciência política e nas disciplinas da administração e políticas públicas, esta tem sido também, de acordo com Mandell (2014), responsável pela dificuldade em desenvolver um framework coerente sobre o desenho, a gestão e a avaliação dessas redes.

Para além desses problemas de coerência teórica, os estudos das redes deparam-se também com claros dilemas no tocante ao desenvolvimento da investigação. Em primeiro lugar, existe um dilema quanto à unidade de análise a utilizar (Klijn e 
Koppenjan (2016, cap. 12) para um maior detalhe): as "redes", com maior enfoque no desenho institucional; os "jogos”, com maior atenção às arenas de negociação, bem como às dinâmicas de interação e seus bloqueios; ou os "atores", com maior enfoque nas suas posições de poder relativas na rede.

Por outro lado, existem alguns dilemas quanto às formas de estudar os resultados das redes e quais os determinantes que condicionam esses resultados. A temática da identificação dos fatores críticos do sucesso colaborativo tem, com efeito, ocupado um especial enfoque nos estudos mais recentes sobre as redes de governação, sobretudo nas tradições de investigação mais ligadas à teoria organizacional e à administração pública. No ponto que se segue analisar-se-ão os principais fatores críticos e principais frameworks de análise.

\section{Fatores críticos para o sucesso das redes de governação}

Antes de avançar para a análise mais aprofundada desses fatores, importa primeiramente explorar o que se deverá considerar como sucesso colaborativo enquanto variável dependente. A esse propósito, uma das primeiras ressalvas necessárias está relacionada com o fato de não ser adequado utilizar as tradicionais noções de eficiência de custos ou de eficácia operacional para avaliar o sucesso de uma rede de governação, as quais são mais adequadas para a análise de sistemas hierárquicos (Torfing et al., 2012; Klijn e Koppenjan, 2016).

Tal como referem diversos autores, os estudos sobre governação em rede deverão debruçar-se sobre os resultados dos processos de colaboração (process outcomes) e não sobre os resultados das políticas públicas (policy outcomes) (Ansell e Gash, 2008; Klijn e Koppenjan, 2016). Bryson et al. (2006) destacam, por exemplo, três níveis de efeitos ou resultados das redes: de primeira ordem, que se referem ao desenvolvimento de capital social, intelectual e político, bem como à promoção de estratégias de atuação mais inovadoras; de segunda ordem, que se relacionam com a coordenação da ação conjunta e a aprendizagem conjunta; e de terceira ordem, que se referem à criação de novas parcerias e/ou de novas instituições, bem como à criação de um ambiente sistêmico menos conflituoso e mais harmonioso.

Considerando o contexto acima descrito, Torfing et al. (2012) propõem, com base no trabalho prévio de um conjunto de outros autores ${ }^{3}$, que o processo de governação em rede seja avaliado em face das promessas que comporta enquanto modo de governação, nomeadamente a capacidade de cumprir os seguintes critérios:

3. Os quatro primeiros objetivos baseiam-se em Provan e Milward (2001), o quinto em Jessop (2002), o sexto em Koppenjan e Klijn (2004). 
- Produzir uma compreensão clara e bem-informada dos problemas societais e das possibilidades de intervenção em causa.

- Gerar opções de políticas públicas inovadoras, proativas e exequíveis que se adequem às perceções dos problemas e dos desafios definidos pelos atores da rede.

- Tomar decisões conjuntas que vão para além do mínimo denominador comum, evitando, ao mesmo tempo, custos excessivos.

- Assegurar uma implementação sem contratempos, com base numa coordenação contínua e num elevado grau de legitimidade e responsabilidade de todos os atores envolvidos.

- Promover ajustes flexíveis das propostas de intervenção e dos serviços face aos feedbacks positivos e negativos e às alterações nas condições, exigências e preferências.

- Criar as condições favoráveis a futuras cooperações através de processos de aprendizagem cognitiva, estratégica e institucional que construam quadros comuns, estimulem um desenvolvimento interdependente e promovam confiança mútua.

De acordo com esses e outros autores, a técnica mais adequada para aferir a eficácia dos processos de colaboração será a análise das perceções dos parceiros envolvidos (ver, inter alia, Ansell e Gash (2008), Chen (2010) e Klijn e Koppenjan (2016)).

Focando agora os fatores críticos para o sucesso dos processos colaborativos inerentes à governação em rede, será importante referir, desde logo, a existência de uma significativa diversidade de abordagens. Em primeiro lugar, Hibbert et al. (2010) distinguem três tipologias de fatores de acordo com o nível de incidência: de nível micro, mais relacionados com práticas concretas dos indivíduos participantes nas redes; de nível macro, relacionados principalmente com a forma como o ambiente institucional externo influencia o funcionamento das redes; e, por fim, de nível meso, relacionados sobretudo com os processos de gestão propriamente ditos e a forma como os desafios das redes evoluem ao longo do tempo.

Por outro lado, importa destacar que, para além do estudo isolado da importância de determinados fatores críticos para o sucesso das redes (para um resumo sobre os fatores mais importantes, ver, inter alia, Sullivan e Skelcher (2002), McQuaid (2010), Hibbert et al. (2010)), alguns autores têm tentado apresentar frameworks de análise que propõem uma organização desses fatores em grupos de variáveis essenciais para explicar o sucesso colaborativo das redes. No âmbito desses frameworks, podem-se salientar as propostas por Bryson, Crosby e Stone (2006), por Thomson e Perry (2006), por Chen (2010), bem como por Ansell e Gash (2008).

Focando a atenção nos frameworks acima referidos, sobretudo no de Ansell e Gash (2008) e de Bryson et al. (2006), considera-se importante distinguir, desde logo, os fatores relacionados com o processo de colaboração propriamente dito daqueles que 
são relativamente "externos" ao mesmo, nomeadamente os antecedentes da rede, o desenho institucional e os processos de liderança.

\section{a) Fatores internos ao processo colaborativo}

Ao nível dos fatores relacionados com os processos de cooperação propriamente ditos, os frameworks referidos destacam que a eficácia desses processos depende essencialmente da capacidade das redes em promover o diálogo, construir relações de confiança e lógicas de ação recíproca, assegurar a dedicação e o compromisso dos diferentes parceiros, criar entendimentos e visões comuns, bem como conseguir resultados intermédios. A propósito do diálogo, Ansell e Gash (2008) referem, por exemplo, que este deverá ser, tanto quanto possível, presencial, de forma a mais facilmente promover a diminuição de eventuais conflitos e estereótipos anteriores, sobretudo quando existem históricos de rivalidade entre alguns parceiros. Já no respeitante à criação de entendimentos e visões comuns, Thomson e Perry (2006) observam que deverá existir uma tentativa de harmonizar os interesses, expectativas e perspectivas de todos os parceiros no processo de definição dos objetivos comuns, sendo, para tal, necessário que os parceiros tenham uma atitude de partilha e transparência, mas também de concessão de parte da sua autonomia. Por fim, Ansell e Gash (2008) referem a importância de ter a oportunidade de celebrar “pequenas vitórias” intermédias, como forma de gerar confiança entre atores e de mobilizá-los para a sua continuidade na rede.

\section{b) Condições iniciais e antecedentes da criação das redes}

Direcionando agora a atenção para os fatores críticos de sucesso "externos” ao processo colaborativo, os frameworks referidos começam por destacar a importância de um grupo de variáveis relacionadas com as condições iniciais ou antecedentes à rede. Nesse grupo encontram-se variáveis como condições contextuais externas e o histórico de desempenho no setor, a legitimidade dos atores, as características dos parceiros, bem como os antecedentes diretos (Ansell e Gash, 2008; Thomson e Perry, 2006; Bryson et al., 2006; Chen, 2010).

Em relação às condições contextuais externas e ao histórico de desempenho no setor, alguns autores referem que existe maior probabilidade de surgirem relações interorganizacionais bem-sucedidas quando o ambiente é complexo, quando há um histórico de problemas de desempenho individual anterior, e quando existe uma interdependência ao nível de recursos, já que essas condições reforçam a necessidade de se desenvolverem relações dessa tipologia (ver, inter alia, Bryson et al. (2006), Thomson e Perry (2006)). 
Já no que concerne à legitimidade organizacional, Chen (2010), Bryson et al. (2006) e Ansell e Gash (2008) apontam que existe maior probabilidade de criação de uma cooperação interorganizacional bem-sucedida quando esse comportamento for encorajado ou mandatado por uma organização financiadora, reguladora ou tutelar, quando puder contribuir para o aumento da reputação da organização, ou quando contribuir para construir uma relação futura de cooperação. A esse propósito, Bryson et al. (2006) assinalam a extrema importância do papel facilitador e mobilizador de organizações ou atores mediadores com legitimidade reforçada (brokering organizations, legitimate conveners e powerful sponsors) que ajudam a chamar a atenção para os problemas e a dirimir barreiras entre organizações (boundary-spanning).

No tocante às características dos parceiros, Chen (2010) e Bryson et al. (2006) referem que há maior probabilidade de as relações interorganizacionais serem mais fortuitas quando os parceiros têm, à partida, visões relativamente semelhantes quanto aos problemas societais subjacentes às redes e aos potenciais objetivos da rede, já que a divergência de visões pode gerar conflitos interorganizacionais. No mesmo sentido, Ansell e Gash (2008) e Bryson et al. (2006) notam que a existência de desequilíbrios de poder entre potenciais parceiros poderá ser inibidora de parcerias, já que pode conduzir a situações de desconfiança e menor compromisso dos atores mais desfavorecidos.

Já em relação aos antecedentes diretos, todos os frameworks em causa apontam experiências prévias de colaboração como fatores facilitadores à criação de redes e ao sucesso do processo colaborativo, na medida em que tendem a aumentar os níveis de confiança mútua e de incorporação (embeddedness) dos atores na rede, e fazem com que os atores já tenham alguma experiência de trabalho em rede, o que diminui os "custos de transação" (ver, inter alia, Ansell e Gash (2008), Thomson e Perry (2006), Bryson et al. (2006) e Chen (2010)). Caso esse histórico não exista, Bryson et al. (2006) consideram que tenderá a haver uma propensão para parcerias mais incrementais, cujo início é caracterizado por acordos informais e menos ambiciosos. Já no caso em que se verifica um histórico de rivalidade entre alguns potenciais parceiros, Ansell e Gash (2008) entendem que a criação de parcerias só será possível se existir uma elevada interdependência entre atores ou se existir uma clara estratégia para ultrapassar os problemas de desconfiança, desrespeito e "estereotipagem".

\section{c) Gestão de redes (ou metagovernação)}

A gestão de redes, também designada na literatura por metagovernação, ocupa especial destaque enquanto fator crítico para o sucesso das redes. Tal como referem Torfing et al. (2012), a metagovernação pode assumir diferentes níveis de interven- 
ção, que pode ser mais ou menos restrita, e diferentes abordagens de intervenção, que pode ser direta (hands-on) ou indireta (hands-off).

Para esses autores (Torfing et al., 2012), o metagovernador tem a seu dispor quatro tipos de estratégias: estratégias de intervenção indireta, quer seja através da construção de narrativas sobre a missão conjunta da rede e da clarificação e moldagem dos interesses, de forma a alinhar os objetivos dos parceiros (goal and framework framing), quer seja através da definição clara dos objetivos da rede, dos membros da mesma e das regras de interação (institutional design); ou estratégias mais interventivas, quer seja através de funções de gestão de processos para reduzir as tensões através do controlo da agenda, da arbitragem dos conflitos e da promoção de aprendizagem mútua (process management), quer seja através da participação direta nas atividades da rede (participation).

Nos pontos que se seguem, ressaltam-se dois fatores críticos destacados por Ansell e Gash (2008), que poderão ser enquadrados sob a designação mais agregadora da metagovernação ou gestão de redes: por um lado, o desenho institucional; e, por outro lado, a liderança facilitadora.

\section{c1) Desenho Institucional}

Direcionando agora atenção para as questôes do desenho institucional, diversos autores referem ser bastante importante definir protocolos e regras básicas, não só quanto a que entidades podem ser parceiras na rede, mas também quanto à forma como os parceiros devem relacionar-se entre si (Ansell e Gash, 2008).

A propósito da pertença à rede, Ansell e Gash (2008) e Nooteboom (2010) consideram que deve existir maior abertura e efetiva possibilidade de participação ativa, de modo a que todos os stakeholders relevantes sejam incluídos, embora se devessem evitar um elevado nível de rotatividade de parceiros (membership turnover) e uma grande "distância cognitiva” entre estes. Assim, Nooteboom (2010) julga necessário distinguir estratégias consoante estejamos perante redes de exploração (exploration) de conhecimento, nas quais a diversidade e a rotatividade de parceiros não constituem grande perigo, e redes de utilização (exploitation) de conhecimento, nas quais terá de haver maior estabilidade ao nível dos membros do projeto.

Ao nível da estrutura de administração das redes, quer Ansell e Gash (2008), quer Bryson et al. (2006) consideram desejável formalizar a estrutura da rede, através da definição clara dos objetivos da rede, das tarefas de cada parceiro, das regras de relacionamento e das estruturas de autoridade. No mesmo sentido, diferentes estudos têm confirmado ser geralmente vantajoso para as redes a existência de uma figura de liderança ou coordenação, desempenhada quer seja por um ou mais membros, 
quer seja por uma entidade externa, sobretudo em situações de elevado número e diversidade de parceiros e de forte desconfiança entre parceiros. Na figura seguinte é possível visualizar uma formulação de Milward, Provan e Kenis, que associam três formas alternativas de governação de redes (governação partilhada, organização líder ou organização de administração da rede) a diferentes características das redes em relação a processos de tomada de decisão e negociação, a níveis de confiança necessários, ou níveis de profissionalização (Milward e Provan, 2006; Provan e Kenis, 2008) - ver Figura 3. Esses autores referem, por exemplo, que a "governação partilhada" das redes é mais adequada para situações em que existem um baixo número de participantes e um elevado nível de confiança, ao passo que a governação através de uma “organização líder" é mais adequada quando existem baixos níveis de confiança, enquanto que a governação através de uma “organização de administração das redes" é mais adequada quando existe um elevado número de membros e há necessidade de um elevado nível de profissionalização da rede (Milward e Provan, 2006; Provan e Kenis, 2008).

\section{FIGURA 3}

Formas alternativas de governação de redes

\begin{tabular}{|c|c|c|c|}
\hline $\begin{array}{c}\text { TIPO DE } \\
\text { FORMA DE } \\
\text { GOVERNAÇÃO }\end{array}$ & $\begin{array}{l}\text { GOVERNAÇÃo } \\
\text { PARTILHADA }\end{array}$ & $\begin{array}{l}\text { ORGANIZAÇÃo } \\
\text { LÍDER }\end{array}$ & $\begin{array}{c}\text { ORganizaÇÃo DE } \\
\text { AdMINISTRAÇÃO DA REDE }\end{array}$ \\
\hline \multicolumn{4}{|l|}{$\begin{array}{l}\text { Configura0ção } \\
\text { gráfica }\end{array}$} \\
\hline Estrutura & $\begin{array}{l}\text { Inexistência de estrutura } \\
\text { administrativa; } \\
\text { Participação na gestão da rede } \\
\text { por todos os membros. }\end{array}$ & $\begin{array}{l}\text { A entidade administrativa (e gestora } \\
\text { da rede) é um membro da rede mais } \\
\text { poderoso. }\end{array}$ & $\begin{array}{l}\text { Entidade administrativa distinta } \\
\text { desenhada para gerir a rede. }\end{array}$ \\
\hline $\begin{array}{l}\text { Número ótimo } \\
\text { de participantes }\end{array}$ & Baixo. & Elevado. & Elevado. \\
\hline $\begin{array}{l}\text { Tomada de } \\
\text { Decisão }\end{array}$ & Descentralizado. & Centralizado. & Misto. \\
\hline Vantagens & $\begin{array}{l}\text { Participação e compromisso dos } \\
\text { membros; fácil formação. }\end{array}$ & $\begin{array}{l}\text { Eficiência; clareza da direção } \\
\text { da rede. }\end{array}$ & $\begin{array}{l}\text { Eficiência na gestão cotidiana; } \\
\text { envolvimento estratégico dos } \\
\text { membros-chave; sustentabi- } \\
\text { lidade. }\end{array}$ \\
\hline Desvantagens & $\begin{array}{l}\text { Ineficiente - encontros frequen- } \\
\text { tes, dificuldade de obter consen- } \\
\text { sos, sem "representante" da rede. }\end{array}$ & $\begin{array}{l}\text { Domínio pela organização líder, } \\
\text { falta de compromisso pelos } \\
\text { membros. }\end{array}$ & $\begin{array}{l}\text { Perceção de hierarquia, custo } \\
\text { de operação, complexidade de } \\
\text { administração. }\end{array}$ \\
\hline
\end{tabular}

Fonte: reprodução autorizada (Milward e Provan, 2006, pp. 22-23). 


\section{c2) Liderança}

Para além das questões relacionadas com a estrutura propriamente dita, os frameworks acima referidos destacam também a extrema relevância da existência de uma ou mais pessoas, ou organizações, que desempenhem, mesmo que de maneira informal, funções de "liderança facilitadora" ou de "gestão de redes”. De acordo com Ansell e Gash (2008), a importância da "liderança facilitadora” advém da necessidade de haver um processo consciente de desenvolvimento de regras de interação, de promoção de confiança, de facilitação do diálogo e de exploração de ganhos mútuos, que se afirma como particularmente significativo quando os incentivos à participação são baixos, ou quando existe assimetria de poder ou um historial de antagonismos.

As funções de liderança são, contudo, diversificadas. A esse propósito, Agranoff e McGuire (2001) identificaram quatro funções centrais à gestão de redes: (a) a ativação (activation), que consiste na identificação e incorporação das pessoas/organizações certas que possuam recursos financeiros, de conhecimento, de autoridade e de capacidade de trabalho; (b) a contextualização (framing), através da qual deverão ser definidas uma estrutura de trabalho e uma distribuição de papéis e desenvolvida uma cultura e identidade da rede; (c) mobilização (mobilizing), de forma a induzir o compromisso dos parceiros; e (d) sintetização (synthesizing), que se caracteriza pela facilitação da interação das relações entre atores, de modo a promover o desenvolvimento de confiança e partilha de informação entre atores.

A propósito do exercício das funções de liderança, importa referir, por fim, que, de acordo com Torfing (2012), estas não têm de ser desempenhadas necessariamente por decisores públicos de topo, mas por qualquer um ou mais atores da rede, desde que estes reúnam um conjunto de condições, tais como: ocupar um lugar central da rede; ser considerado pelos outros atores como um ator com legitimidade; ter acesso e comandar recursos-chave; e ter capacidade organizacional para monitorizar e gerir as redes.

\section{A Importância da metagovernação para o sucesso das redes de governação: uma reflexão com base nos contextos português e brasileiro}

A definição de estratégias de metagovernação assume, de acordo com alguns autores, especial importância para a governação pública em rede, na medida em que é necessário conseguir articular com outros modos de governação, sobretudo os mais tradicionais, os quais coexistem, de forma nem sempre pacífica, na medida em que têm entre si complementaridades, mas também conflitualidades (Meuleman 2008). 
A temática da articulação entre as redes e as hierarquias é de especial importância em contextos como o português ou o brasileiro, nos quais ainda predomina uma abordagem à governação pública hierarquizante e politizada, que está em linha com a tradição administrativa napoleônica de ambos os países, mas onde se recorre frequentemente a modos de governação colaborativa, dando, assim, origem a falhas diversas (Mota et al., 2014; Gomes e Secchi, 2015).

No caso português, um estudo recente que analisou os processos de reforma da governação pública em Portugal, numa perspectiva comparada em termos europeus, demonstrou, por exemplo, que persistem no país (tal como em outros países da Europa do Sul) claros défices de coordenação entre diferentes atores e níveis de governação e entre diferentes setores de políticas públicas, referindo ainda que os mecanismos de coordenação predominantes nesses países são os relacionados com a hierarquia e o recurso a atores políticos de topo (Mota et al., 2014; Lægreid et al., 2016).

O fraco desempenho ao nível da coordenação entre atores em Portugal contrasta, contudo, com a indicação da colaboração e cooperação entre diferentes atores como uma das principais tendências de reforma da governação pública por parte de um largo número de dirigentes públicos inquiridos (Mota et al., 2014; Mota et al., 2016).

Assim, considera-se necessário procurar identificar os fatores críticos de casos de sucesso e insucesso na governação pública em rede em Portugal. A esse propósito, importa realçar alguns estudos que referem que os domínios da governação local e da cooperação intermunicipal têm sido geradores de alguns casos de boas práticas, os quais foram claramente facilitados por experiências anteriores de cooperação entre parceiros, bem como por dinâmicas de liderança facilitadora (Teles, 2016). Num outro trabalho, Marques (2017) destaca ainda como casos de boas práticas o Centro Nacional de Apoio ao Imigrante e a Comissão de Proteção de Crianças e Jovens da Amadora no âmbito de práticas de governação integrada (ou em rede) de problemas sociais complexos, identificando como fatores críticos a liderança, para além da participação das partes interessadas, e uma boa comunicação, sobretudo de caráter informal e sem excesso de informação.

No caso da governação pública brasileira, Gomes e Martins (2013) dão conta de que esta se caracteriza por uma significativa centralização de poder no nível federal e por um claro problema de fragmentação entre atores no nível do governo, havendo tendência para aumento da competição por atenção presidencial da parte dos organismos do Estado, gerando, assim, um clima de desconfiança. Para esses autores, tais problemas devem-se, entre outros aspectos, à proliferação de órgãos de primeiro escalão, à debilidade das instâncias de coordenação, que passaram a ter um perfil demasiadamente tecnicista, bem como à emergência de diferentes comu- 
nidades epistêmicas no seio da administração pública brasileira (Gomes e Martins, 2013). De acordo com Gomes e Martins (2013), esse quadro dificulta o sucesso das múltiplas iniciativas de governação de políticas públicas em rede, as quais têm nascido, segundo Gomes e Secchi (2015), num quadro de algum descrédito dos atores políticos tradicionais e de uma sociedade civil ativa, com grupos de interesse a reclamarem por maior participação na definição de políticas públicas.

A propósito das diferentes iniciativas de governação pública em rede no Brasil, importa salientar o papel pioneiro da implantação dos conselhos de políticas públicas a partir da promulgação da Constituição brasileira de 1988, nos quais decorrem processos de discussão, deliberativos ou consultivos, em que participam não apenas atores do Estado (nomeadamente dirigentes públicos), mas também atores societais, sobretudo cidadãos/utilizadores, sindicatos, universidades e organizações sem fins lucrativos (Ronconi et al., 2018; Gomes e Secchi, 2015). De acordo com Gomes e Secchi (2015), os conselhos têm lugar nos três níveis de governo (federal, estadual e municipal) e em diferentes áreas setoriais, das quais se destacam, pela relevância que esses instrumentos têm, as da Educação, Saúde, Segurança Social, Infância e Juventude, Cultura, Desenvolvimento Econômico e Ambiente.

Na gestão dessas redes, os conselhos gestores exercem papel de metagovernador. Como metagovernadores, os conselhos gestores comportam-se de modo estratégico ao cooperarem para o controlo societal e o aumento da accountability no exercício do poder e da democracia (Gomes e Secchi, 2015). Todavia, estudos de outros autores observam as práticas realizadas pelos conselhos gestores de políticas públicas como não suficientes para assegurar a condução democrática, na medida em que não constituem um conjunto que funciona ou se desenvolve de modo natural, espontâneo e homogêneo (Carvalho et al., 1999; Gomes, 2015). No mesmo sentido, Gomes e Secchi (2015) consideram que o cumprimento dos objetivos dos conselhos de políticas públicas é prejudicado, sobretudo em contextos mais estreitos, pela falta de cultura participativa e conhecimento técnico por parte dos cidadãos, bem como pela "captura" desses fóruns por grupos mais organizados.

Como é possível observar, os fatores da liderança e da institucionalização de regras e de organismos de governação das redes afirmam-se como os mais evidentes nos estudos empíricos sobre os contextos nacionais descritos. Não se mostrando como novidade face ao quadro teórico apresentado anteriormente, será importante salientar que esses fatores se afirmam como particularmente essenciais em contextos com uma reduzida "cultura de parceria" como são os casos português ou brasileiro. 


\section{Notas finais}

A governação em rede tornou-se, tal como evidenciado na seção introdutória, um modo de governação pública bastante frequente em diversos países ao longo das últimas décadas, sendo alvo de algum interesse científico, embora em menor escala do que seria desejável, o que tem conduzido à subsistência de alguns mitos durante muito tempo.

Um desses mitos funda-se no fato de as redes e parcerias serem frequentemente entendidas como formas de governação sem variação, o que não corresponde à verdade, na medida em que existem diferentes tipos, os quais têm objetivos com diferentes níveis de ambição e, como tal, diferentes níveis de exigência para a sua subsistência (seção II). A diferença entre tipologias de redes é de tal forma clara que tem dado origem, inclusivamente, a diferentes tradições de estudo ou diferentes abordagens teóricas e metodológicas (seção III).

Um outro mito foi alimentado durante a designada primeira geração do estudo das redes, no âmbito da qual se acreditava que as redes e parcerias apenas comportavam benefícios e eram autorreguláveis. Esse mito tem sido, entretanto, quebrado face às evidências de potenciais desvantagens e limitações das redes (ver seção II) e ao estudo dos fatores críticos para o sucesso das redes, entre os quais se destaca a gestão de redes (ou metagovernação) (seção IV). Esse fator crítico parece ser particularmente importante em contextos, como o português ou o brasileiro, em que não existem muitos antecedentes de cooperação e persistem desequilíbrios de poder entre atores (seção v).

Assim, conclui-se que a governação em rede está longe de ser a panaceia da governação pública e que requer uma atenção particular ao longo de todo o processo de colaboração entre os parceiros, de forma a que a mesma não resulte em fracassos. Para tal, é necessário ter em consideração um vasto conjunto de fatores críticos que a literatura já identificou, mas cuja relevância não é de aplicação universal. Nesse sentido, considera-se particularmente pertinente o desenvolvimento de mais investigação empírica em diferentes contextos de governação, sobretudo naqueles em que existe maior possibilidade para a ocorrência de falhas, como são os contextos português e brasileiro. Espera-se que este artigo seja um bom ponto de partida para esses estudos. 
VII. Referências Bibliográficas

AgranOfF, Robert. (2003), Leveraging networks: a guide for public managers working across organizations. Arlington, IBM Endowment for The Business of Government.

Agranoff, Robert \& McGuire, Michael. (2001), "Big questions in public network management research". Journal of Public Administration Research and Theory, 11 (3): 295-326.

Ansell, Chris \& GASH, Alison. (2008), "Collaborative governance in theory and practice". Journal of Public Administration Research and Theory, 18 (4): 543-571.

BOUCKAERT, Geert et al. (2010), The coordination of public sector organizations: shifting patters of public management. Houndmills, Palgrave Macmillan.

Bryson, John et al. (2006), "The design and implementation of cross-sector collaborations". Public Administration Review, 66 (special issue): 44-55.

Carvalho, Juvenilda et al. (1999) "Conselhos municipais: sua contribuição para o desenvolvimento local”. Anais do Enanpad, 23 (CDROM).

Chen, Bin. (2010), "Antecedents or processes? Determinants of perceived effectiveness of interorganizational collaborations for public service delivery". International Public Management Journal, 13 (4): 381-407.

Gomes, Eduardo. (out. /dez. 2015), “Conselhos gestores de políticas públicas: aspectos teóricos sobre o potencial de controle social democrático e eficiente”. Cad. Ebape.BR, 13 (4): 894-909.

Gomes, Ricardo Corrêa \& Martins, Humberto. (2013), “Tendências e perspectivas da administração pública no Brasil”. Revista de Pesquisa em Políticas Públicas, 1: 30-62

Gomes, Ricardo Corrêa \& Secchi, Leonardo. (2015), "Public administration in Brazil: structure, reforms, and participation”. In: MAssey, Andrew \& JoHnston, Karen (eds.). The international handbook of public administration and governance. Cheltenham, Edward Elgar, pp. 227-246.

Hibbert, Paul et al. (2010), “Managing collaborative inter-organizational relations”. In: CroPER, Steve et al. (eds.), The Oxford handbook of inter-organizational relations. New York, Oxford University Press, pp. 390-416.

Jessor, B. (2002), The future of the capitalist state. Cambridge: Polity Press.

KEAST, Robyn et al. (fev. 2007), "Getting the right mix: unpacking integration meanings and strategies”. International Public Management Journal, 10 (1): 9-33.

KiCKERT, Walter et al. (1997), “Conclusion: strategies for network management”. In: KiCKERT, Walter et al. (eds.). Managing complex networks: Strategies for the public sector. London, Sage, pp. 166-191.

Klijn, Erik-Hans \& Koppenjan, Joop. (2016), Governance networks in the public sector. Abingdon, Routledge.

Koolman, Jan (ed.). (1993), Modern governance: new government-society interaction. London, Sage. 
Koppenjan, J. \& KLIJn, E.-H. (2004). Managing uncertainties in networks: a network approach to problem solving and decision making. Londres, Routledge.

LÆGREID, Per et al. (2016), “Coordination challenges and administrative reforms”. In: HAMMERSCHMID, Gerhard et al. (eds). Public administration reforms in Europe: the view from the top. Cheltenham, Edward Elgar, pp. 244-258.

Mandell, Myrna. (2014), “Introduction”. In: KeAst, Robyn et al. (eds.). Network theory in the public sector. Nova York, Routledge, pp. 3-14.

Mandell, Myrna. (1990), "Network management: strategic behaviour in the public sector". In: GAGE, Robert \& MANDELL, Myrna (eds.). Strategies for managing intergovernmental policies and networks. Nova York, Praeger, pp. 20-53.

Marques, Rui. (2017), Problemas sociais complexos e governação integrada. Lisboa, 699 p., tese de doutorado, Universidade de Lisboa.

MCQUAID, Ronald. (2010), "Theory of organizational partnerships: partnership advantages, disadvantages and success factors". In: OsBorne, Stephen (ed.). The new public governance? Emerging perspectives on the theory and practice of public governance. Abingdon, Routledge, pp. 127-148

Meuleman, Louis. (2008), Public management and the metagovernance of hierarchies, networks, and markets: The feasibility of designing and managing governance style combinations. Netherlands, Heidelberg.

Milward, H. Brinton \& Provan, Keith G. (2008), A manager's guide to choosing and using collaborative networks. Washington, Івм Center for the Business of Government.

Mota, Luís F. et al. (2014), "Reforma do setor público em Portugal: visões e experiências de dirigentes de topo". Relatório de Portugal para o workpackage 3 do Projeto Cocops, Lisboa. Disponível em https://www.researchgate.net/profile/Luis_Mota5/contributions.

Mota, Luís F. et al. (2016), "Public sector reform in Portugal: a path between service improvement and cutback measures". In: Hammerschmid, Gerhard et al. (eds.), Public administration reforms in Europe: the view from the top. Cheltemham, Edward Elgar, pp. 194-204.

Nоотевоом, Bart. (2010), "Learning and innovation in inter-organizational relationships". In: Cropper, Steve et al. (eds.). The Oxford handbook of inter-organizational relations. Nova York, Oxford University Press, pp. 607-634.

Osborne, Stephen. (2010), "Introduction: The (new) public governance: a suitable case for treatment?". In: OsBorne, Stephen (ed.). The new public governance?: Emergingperspectives on the theory and practice of public governance. Abingdon, Routledge, pp. 1-16.

Peters, B. Guy. (2010), “Meta-governance and public management”. In: Osborne, Stephen (ed.). The new public governance? Emerging perspectives on the theory and practice of public governance. Abingdon, Routledge, pp. 36-51.

Provan, Keith \& Kenis, Patrick. (2008), "Modes of network governance: structure, management, and effectiveness". Journal of Public Administration Research and Theory, 18 (2): 229-252. 
Provan, K. \& Milward, H. B. (2001), “Do networks really work? A framework for evaluating public-sector organizational networks". Public Administration Review, 61 (4): 414-423.

Rhodes, R. A. W. (1997), Understanding governance: policy networks, governance, reflexivity and accountability. Maidenhead, Open University Press.

Ronconi, Luciana et al. (2018), "Inovação social na saúde: o caso dos Conselhos de Florianópolis". In: Matos, Pedro V. et al. (eds.). Inovação social: estudo de casos na comunidade de países de língua portuguesa. Coimbra, Almedina.

Sørensen, Eva \& Torfing, Jacob. (2007), "Introduction: governance network research: towards a second generation”. In: SørEnSEN, Eva \& ToRfIng, Jacob (eds.). Theories of democratic network governance. Houndmills, Palgrave Macmillan, pp. 1-21.

Sullivan, Helen \& SKelCher, Chris. (2002), Working across boundaries: collaboration in public services. Basingstoke, Palgrave Macmilan.

TELES, Filipe. (2016), Local governance and inter-municipal cooperation. Houndmills, Palgrave Macmillan.

Thomson, Ann M. \& Perry, James. (2006), “Collaboration process: Inside the black box”. Public Administration Review, 66 (special issue): 20-32.

Torfing, Jacob. (2012), “Governance networks”. In: Levi-Faur, David (ed.). The Oxford handbook of governance. Nova York, Oxford University Press, pp. 99-112.

Torfing, Jacob et al. (2012), Interactive governance: advancing the paradigm. Nova York, Oxford University Press.

\section{Resumo}

Governação pública em rede: contributos para sua compreensão e análise (em Portugal e no Brasil) Este artigo pretende apresentar uma revisão crítica da literatura sobre a governação pública em rede, abordando as diferentes tipologias de redes, os seus benefícios e desafios, as principais abordagens teóricas e metodológicas do seu estudo e os fatores críticos para o seu sucesso, em particular nos contextos da governação pública em Portugal e no Brasil. A relevância da análise decorre de este modo de governação ser crescentemente usado em diversos países, mas ser ainda alvo de pouca atenção acadêmica e política, sobretudo em contextos com tradição de governação hierárquica, tal como acontece nesses dois países. Assim, consideram-se essenciais contributos para compreender este fenômeno e fomentar a sua análise em tais contextos.

Palavras-chave: Redes; Governação Pública; Fatores Críticos; Portugal; Brasil. 


\section{Abstract}

Network Public Governance: contributions for its understanding and analysis (in Portugal and in Brazil)

This article aims to present a critical literature review on network public governance, analysing the different typologies of networks, their benefits and challenges, the main theoretical and methodological approaches of their study and the critical factors for their success, particularly within the public governance contexts of Portugal and Brazil. The relevance of this analysis stems from this governance mode being increasingly used in several countries, although still being subject to little academic and political attention, namely in contexts with a hierarchical governance tradition, such as in these two countries. Thus, contributions to understand this phenomenon and to foster its analysis in such contexts are considered essential. Keywords: Networks; Public Governance; Critical Factors; Portugal; Brazil.

Texto recebido 26/06/2018 e aprovado em 18/11/2018.

DOI: $10.11606 / 0103-2070 . t s .2019 .147567$

Luis F. МотA tem doutoramento em administração pública pela Universidade de Lisboa e desenvolve investigação nos domínios da governação em rede, do processo de políticas públicas, da reforma do setor público e da governação local. Atualmente, é professor auxiliar convidado na Universidade de Aveiro e investigador na Unidade de Investigação em Governança, Competitividade e Políticas Públicas (GOvCOpp) da mesma universidade. E-mail: luismota@ua.pt.

Bernadete Bittencourt é doutora em sociologia econômica e das organizações pela Universidade de Lisboa. Professora auxiliar convidada do Departamento de Ciências Sociais, Políticas e do Território, Universidade de Aveiro. Investigadora da unidade de investigação em governança, competitividade e políticas públicas, Universidade de Aveiro (Govcopp) e do laboratório de investigação em ciências sociais e gestão (cSG/Lisbon School of Economics and Management), Universidade de Lisboa. E-mail: bernadete@ua.pt. 